\title{
MORPHONOTACTICS IN L1 ACQUISITION OF LITHUANIAN: TD VS. SLI
}

\author{
Laura Kamandulytè-Merfeldienè
}

\begin{abstract}
The aim of the present study is to test the Strong Morphonotactic Hypothesis (SMH), according to which speakers use morphonotactic consonant clusters as morphological boundary signals (Korecky-Kröll et al. 2014). It is hypothesized that morphonotactic clusters will be better retained during production than phonotactic clusters due to the function fulfilled by a morpheme. The study is based on experimental data collected from 60 Lithuanian TD children and 11 Lithuanian SLI children.

This study explores the impact of morphology on the acquisition of phonotactics. The findings suggest that TD children process morphonotactic clusters more accurately than phonotactic clusters because morphonotactic clusters have the function of co-signalling the existence of a morphological rule. In contrast to TD children, for SLI children prototypical morphonotactic clusters are the most difficult as SLI children are not sensitive to morphological information which is carried by morphonotactic clusters.*
\end{abstract}

Keywords: morphonology, consonant cluster, phonotactics, morpheme, morpheme boundary, Lithuanian

\section{Introduction}

This paper will discuss the acquisition of Lithuanian phonotactics and morphonotactics, i.e. consonant clusters occurring within morphemes and across morpheme boundaries. Morphonotactics is the area of interaction between morphotactics and phonotactics and represents a subfield of morphonology which in turn is the area of interaction between morphology and phonology (Dressler at al. 2010: 51). Morphonotactics is a new research field which has been established in recent years (Dressler, Dziubalska-Kołaczyk 2006a, 2006b) and concerns the co-occurrence of sounds at morpheme boundaries. According to Wolfgang U. Dressler, Katarzyna

* The author is grateful to Prof. Ineta Dabašinskiene and all the colleagues who took part in the CLAD project. The 
Dziubalska-Kołaczyk and Lina Pestal (2010: 52), a morphonotactic consonant cluster is a cluster which occurs only through morphotactic operations. Phonotactic preferences hold for the basic forms of monomorphemic words; the less they are respected, the more marked phonotactic sequences arise. Morphonotactic sequences, on the other hand, which are due to morphological operations of inflection or word-formation, are much more likely to be marked (Dressler et al. 2010). ${ }^{1}$ Based on these theoretical propositions, the paper focuses on the acquisition of phonotactic and morphonotactic consonant clusters in Lithuanian. The aim of the study is to test the Strong Morphonotactic Hypothesis (SMH), according to which speakers use morphonotactic consonant clusters as morphological boundary signals (Korecky-Kröll et al. 2014, Calderone et al. 2014: 59). It is hypothesized that morphonotactic clusters will be better retained in production than purely phonotactic clusters due to the function fulfilled by a morpheme.

Although studies exploring the acquisition of morphonotactics are rare (Kamandulytė 2006a, 2006b, Marshall, van der Lely 2006, Freiberger 2007, Zydorowicz 2007, 2010), they show that morphological information plays a significant role in the acquisition of morphonotactic clusters. Being a strongly inflected fusional language with a very rich inflectional and derivational morphology, Lithuanian represents an especially interesting case for the study of the acquisition of morphonotactics. Some preliminary research based on the longitudinal data of one Lithuanian child support the hypothesis that morphonotactic clusters are acquired earlier and processed faster and more accurately than purely phonotactic clusters (Kamandulytė 2006a, 2006b). This study presents experimental data collected from 60 typically developing (TD) children. In addition, experimental data of 11 children with specific language impairment ${ }^{2}$ (SLI) were included in order to test the claim that SLI children perform better on monomorphemically legal clusters than on monomorphemically illegal clusters (Marshall, van der Lely 2006).

The paper is structured as follows. Section 2 focuses on the features of morphonotactics in Lithuanian and presents the types of Lithuanian (mor)phonotactic clusters. Section 3 describes the methodology of testing. Section 4 presents the results of the study. Section 5 discusses the role of morphology in the acquisition of morphonotactic clusters and provides conclusions.

\section{Morphonotactics in Lithuanian}

Based on the morphonotactic classification (Dressler, Dziubalska-Kołaczyk 2006a: 83), Lithuanian consonant clusters can be graded according to the role of morphology and phonotactics:

(a) Prototypical morphonotactic clusters (monomorphemic illegal), i.e. clusters which are exclusively due to morphological operations and never occur in monomorphemic words. As we see in the Table $1^{3}$, many word final consonant clusters in Lithuanian are prototypical morphonotactic clusters.

\footnotetext{
1 According to W. U. Dressler et al. (2010: 65) the prediction that morphonotactic consonantal clusters are more marked (either universally or language-specifically) than intramorphemic phonotactic ones appears to hold true for inflection and, largely, derivation, but not for compounding. The theoretical basis of universal markedness (or universal preferences) draws on models of Natural Phonology (see Hurch, Rhodes 1996) and Natural Morphology (see Dressler et al. 1987).

2 Specific language impairment (SLI) is a developmental language disorder which can affect both comprehension and production of language and is not linked to any other developmental disorders or neurological conditions such as learning disabilities, autism, Williams Syndrome or brain injury (Leonard 1998).

3 The classification of Lithuanian clusters is based on the examples from the Corpus of Spoken Lithuanian http:// donelaitis.vdu.lt/sakytines-kalbos-tekstynas/ (24.2.2015) and the corpora of two Lithuanian children.
} 
Usually they are formed by the second-person singular imperative in $-k$, e.g. lip-k (climb-IMP.2SG) and by the third-person future in -s, e.g. rakin-s (lockFUT.3). Morphonotactic clusters that occur in medial position are formed by the plural imperative in - $k$, e.g. lip-k-ite (climb-IMP-2PL), the imperfect in - $d$, e.g. šok-dav-o (dance-IMPF-3), and very rarely by the future in -s, e.g. rakin-s-ite (lock-FUT-2PL). Looking at the Table 1, we see that prefixing sometimes creates morphonotactic clusters, as in at-neš-ti (PFX-bring-INF).

Table 1. Morphonotactic clusters

\begin{tabular}{|c|c|c|}
\hline Cluster & Position & Example \\
\hline & & Imperative \\
\hline \multirow{2}{*}{$p k$} & medial & lip-k-ite (climb-IMP-2PL) \\
\hline & final & lip-k (climb-IMP.2sG) \\
\hline \multirow{2}{*}{$b k$} & medial & dirb-k-ite (work-IMP-2PL) \\
\hline & final & dirb-k (work-IMP.2sG) \\
\hline \multirow{2}{*}{$m k$} & medial & im-k-ite (take-IMP-2PL) \\
\hline & final & im-k (take-IMP.2sG) \\
\hline sk & final & skris-k (fly-IMP.2sG) \\
\hline lk & final & kel-k (lift-ıMP.2sG) \\
\hline$r k$ & final & bar-k (scold-IMP.2sG) \\
\hline$z ̌ k$ & final & lauž-k (break-IMP.2sG) \\
\hline \multicolumn{3}{|r|}{ Future } \\
\hline \multirow{2}{*}{ ns } & medial & rakin-s-ite (lock-FUT-2PL) \\
\hline & final & rakin-s (lock-FUt.3) \\
\hline ps & final & kep-s (bake-Fut.3) \\
\hline bs & final & dirb-s (work-FUt.3) \\
\hline Is & final & kel-s (lift-FUt.3) \\
\hline ks & final & pyk-s (be angry-fut.3) \\
\hline \multicolumn{3}{|r|}{ Imperfect } \\
\hline$k d$ & medial & šok-dav-o (dance-IMPF-3) \\
\hline$m d$ & medial & stum-dav-o (push-IMPF-3) \\
\hline \multicolumn{3}{|r|}{ Prefixes } \\
\hline tn & medial & at-neš-ti (PFX-bring-INF) \\
\hline šp & medial & iš-pil-ti (PFX-pour_out-INF) \\
\hline ts & medial & at-si-sés-ti (PFX-REFL-sit_down-INF) \\
\hline
\end{tabular}

(b) Clusters which are morphonotactic as a strong default or (c) as a weak default, i.e. morphologically motivated clusters with very few phonotactic exceptions in (b) and more phonotactic exceptions in (c). As it is difficult to establish a boundary between types (b) and (c), Lithuanian examples of both types are presented in one table. Lithuanian clusters that are morphonotactic as defaults occur in medial or final position (see Table 2). Medial clusters arise from the concatenation of a consonant-final root and the future suffix -s, e.g. ger-s-i (drink- FUT-2SG), the imperative suffix - $k$, e.g. gul-k-ite (lie_on-IMP-2PL), and the infinitive suffix-ti, e.g. im-ti (take-INF). Morphonotactic default clusters that occur in word-final position are formed by third person future forms in $-s$, e.g. ger-s (drink-FUT.3). 
Table 2. Morphonotactic default clusters

\begin{tabular}{|c|c|c|c|}
\hline Cluster & Position & $\begin{array}{l}\text { Within morpheme } \\
\text { (phonotactic) }\end{array}$ & $\begin{array}{l}\text { Across morphemes } \\
\text { (morphonotactic) }\end{array}$ \\
\hline \multicolumn{4}{|c|}{ Future } \\
\hline \multirow{2}{*}{ rs } & medial & gars-as (sound-NOM.SG) & ger-s-i (drink-FUT-2sG) \\
\hline & final & nors (though) & ger-s (drink-FUT.3) \\
\hline$r s^{2}$ & medial & virš-us (top-NOM.sG) & pamir-š-i (forget-FUT-2sG) \\
\hline \multirow[t]{2}{*}{$m s$} & medial & tams-us (dark-NOM.sG) & im-s-i (take-FUT-2sG) \\
\hline & final & draug-ams (friend-DAT.PL) & im-s (take-FUt.3) \\
\hline Is & medial & bals-as (voice-NOM.sG) & gul-s-i (lie-FUt-2sG) \\
\hline ps & medial & liepsn-a (flame-Nom.sG) & sup-s-i (swing-FUT-2sG) \\
\hline ks & medial & keks-as (cake-NOM.SG) & susitik-s-i (meet-FUT-2sG) \\
\hline \multicolumn{4}{|r|}{ Infinitive } \\
\hline$m t$ & medial & rimt-as (serious-NOM.SG) & gim-ti (be born-INF) \\
\hline št & medial & aštuon-i (eight-NOM.PL) & pieš-ti (draw-INF) \\
\hline \multicolumn{4}{|c|}{ Imperative } \\
\hline Ik & medial & vilk-as (wolf-NOM.sG) & gul-k-ite (lie_on-IMP-2PL) \\
\hline$z ̌ k$ & medial & kažk-as (something-NOM.SG) & lauž-k-ite (break-ıMP-2PL) \\
\hline
\end{tabular}

(d) clusters which exist both due to morphology and without interaction with morphology (monomorphemic legal). Clusters that occur across morpheme boundaries usually are formed by plural imperatives in - $k$, e.g. $g$ er-k-ite (drinkIMP-2PL) and infinitives in -t, e.g. veik-ti (do-INF) (see Table 3). These clusters occur in the medial position.

Table 3. Monomorphemic legal clusters

\begin{tabular}{|l|l|l|l|}
\hline \multicolumn{1}{|c|}{ Cluster } & Position & \multicolumn{1}{|c|}{$\begin{array}{c}\text { Within morpheme } \\
\text { (phonotactic) }\end{array}$} & \multicolumn{1}{|c|}{$\begin{array}{c}\text { Across morphemes } \\
\text { (morphonotactic) }\end{array}$} \\
\hline \multicolumn{5}{|c|}{ Imperative } \\
\hline$r k$ & medial & agurk-as (cucumber-NOM.SG) & ger-k-ite (drink-IMP-2PL) \\
\hline$n k$ & medial & rank-a (hand-NOM.SG) & skambin-k-ite (call-IMP-2PL) \\
\hline$s k$ & medial & visk-as (all-NOM.SG) & mes-k-ite (throw-IMP-2PL) \\
\hline \multicolumn{5}{|c|}{ Infinitive } \\
\hline$k t$ & medial & nakt-is (night-NOM.SG) & veik-ti (do-INF) \\
\hline$s t$ & medial & kopūst-as (cabbage-NOM.SG) & žais-ti (play-INF) \\
\hline$n t$ & medial & spint-a (cupboard-NOM.SG) & skin-ti (pick-INF) \\
\hline It & medial & gelton-as (yellow-NOM.SG) & gul-ti (lie_on-INF) \\
\hline
\end{tabular}

(e) Clusters which never come into being due to morphology (only phonotactic), e.g. initial clusters in a language which have neither monoconsonantal prefixes, nor morphological deletion of the first vowel of a word. A lot of Lithuanian onomatopoeic words belong to this class, e.g. apči 'atishoo'.

According to Wolfgang U. Dressler and Katarzyna Dziubalska-Kołaczyk (2006a: 83), prototypical morphonotactic clusters (a) have the function of co-signalling the existence of a morphological rule; morphonotactic default clusters (b) and (c) perform this function less adequately, while phonotactic clusters of the type (d) 
and (e) cannot perform this function and therefore they may be called prototypical phonotactic clusters.

The aforementioned division of consonant clusters according to their position in words and morphemic compositions of words is essential when analysing the processes of language acquisition and studying whether the position of consonant clusters within words has any influence on their acquisition.

\section{Testing methodology}

To achieve the goals listed above, a test on phonotactic and morphonotactic clusters has been chosen. This test has been developed for the CLAD (Crosslinguistic Language Diagnosis) project ${ }^{4}$ initiative. The CLAD project focused on language acquisition in typically developing children and in children affected by language impairments. One of the goals of the project was to develop a set of clinical markers to identify children at risk of specific language impairments.

The methodology of the test on phonotactic and morphonotactic clusters was suggested by Wolfgang U. Dressler and has been adapted to Lithuanian by Laura Kamandulytè-Merfeldienè. The lexical content of the sentences in the test was carefully controlled. The Lithuanian words with consonant clusters, like the other words in the test, were selected from the corpora of Lithuanian children (age $1 ; 8-4 ; 3$ ). The procedure of the test included 2 tasks, a production task and a repetition task. We conducted pre-experimental testing with both production and repetition tasks before conducting the final testing.

The participants in the final testing were 60 TD children (3-7 years old) and 11 SLI children (6-7 years old) from kindergarten divided into several age groups (summarized in Table 4). Unfortunately, the sample of SLI children was rather small. The criterion for selecting the children was lower than that used in most studies of SLI as SLI is not diagnosed yet in Lithuania; speech therapists are still not aware of it and consequently there are no standardized diagnostic tests. Besides, there is considerable heterogeneity among children that are diagnosed with language impairments, so to be able to select children with SLI and not some other disorder, we started from a large group of children in 3 different kindergartens, 2 of which specialize in helping children with special needs. The children that were expected to have SLI were directed to us by speech therapists as having some language impairment. Control subjects have been recruited from a group of TD children.

The grammar and phonology screening (GAPS) test (van der Lely et al. 2007) 5 was used as a main tool for selecting SLI children, as in Lithuania there is no standardized test to diagnose SLI. Lithuanian speech therapists use a non-standardized test (Gaulienè et al. 2000), which was also used in our subject selection as the starting point since no better available testing materials were available. If the child's performance was poor on both GAPS-LT and the non-standardized Lithuanian test, such child was considered to have an SLI.

After selecting children according to the linguistic and general developmental criteria, each of the selected children was tested individually in a separate room. Each testing session lasted about ten minutes. The responses were audiotaped.

\footnotetext{
4 The European Project CLAD (2008-2011) was funded by the Lifelong Learning Programme and coordinated by Professor Maria Teresa Guasti of the Dept. of Psychology of the University of Milano-Bicocca. The project involved Austria, Belgium, Germany, Italy, Lithuania, and Romania. http://www.cladproject.eu/ (24.2.2015)

5 The GAPS test has been adapted to Lithuanian by Ineta Dabašinskienè and Jūrate Ruzaitè (for information about the adaptation see Ruzaite, Dabašinskienè 2010).
} 
Table 4. Subjects for the morphonotactic test

\begin{tabular}{|c|c|c|c|c|c|}
\hline & \multicolumn{4}{|c|}{ TD } & SLI \\
\hline Age & $3-4^{6}$ & $4-5$ & $5-6$ & $6-7$ & $6-7$ \\
\hline Boys & 7 & 8 & 5 & 5 & 11 \\
\hline Girls & 8 & 7 & 10 & 10 & 0 \\
\hline \multirow{2}{*}{ Total } & 15 & 15 & 15 & 15 & 11 \\
\hline & \multicolumn{4}{|c|}{60} & 11 \\
\hline
\end{tabular}

\subsection{Production task}

The targeted categories of the production task included:

- morphonotactic (monomorphemic illegal) clusters $n s, p k, m k$ (type (a) according to morphonotactic classification, see chapter 2),

- $\quad$ morphonotactic default clusters št, $m t, p s, k s$, lk (types (b), (c) according to morphonotactic classification),

- monomorphemic legal clusters $n t, l t, n k, s k$ (type (d) according to morphonotactic classification).

Pictures and stimulus sentences were used in the production task. A picture on a computer screen was shown to the child for each experimental item. Furthermore, pre-recorded audio stimuli were played from the computer. The child's task was to use the verb that is produced in the pre-recorded audio in an appropriate form. The first part of the task required the participants to use infinitive forms containing morphologically motivated consonant clusters, e.g. while presenting the picture (see Figure 1) the following sentence (1a) was played:

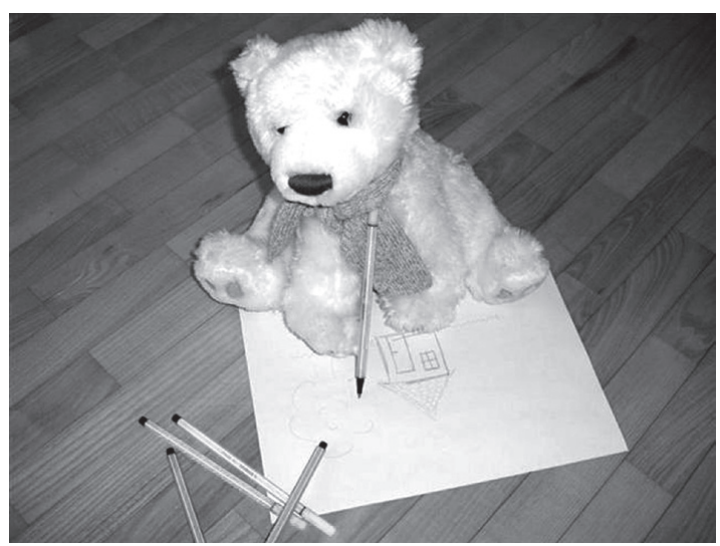

Figure 1. The picture used in the production task
(1a) I:
Meškiukas
piešia.
Paklausk, ar jam patinka tai daryti?
draw:PRS.3
'The teddy-bear is drawing. Ask him if he likes to do that?'

The present form was used for audio stimuli, and participants were required to say the sentence with the infinitive form (1b). 
$\begin{array}{llllll}\text { (1b) CH: } & \text { Meškiuk, } & \text { ar } \quad \text { tau } & \text { patinka } & \text { pieš-ti? } \\ & \text { teddy-bear.voc.SG } \quad \text { Q you:DAT } & \text { like:PRs.3 } & \text { draw-INF } \\ & \text { 'Teddy-bear, do you like drawing?’7 } & & \end{array}$

In the second part of the task the participants were required to use the future tense (2), and in the third part they were required to use the imperative (3):

(2) I: Meškiukas sutinka draugus.

teddy-bear:NOM.SG meet:PRS.3 friend:ACC.PL

Paklausk, ar jis darys tai rytoj?

'The teddy-bear is meeting friends. Ask him if he will do that tomorrow?'

$\mathrm{CH}$ : Meškiuk, ar tu sutik-s-i draugus?

teddy-bear:voc.sG Q you.NOM meet-FUT-2SG friend:ACc.PL

'Teddy-bear, will you meet friends?'

(3) I: Meškiukai nenori skambinti.

teddy-bear:NOM.PL want:PRS.3:NEG call:INF

Paprašyk, kad jie paskambintų.

'The teddy-bears don't want to call. Ask them to call.'

$\mathrm{CH}$ : Meškiukai, $\quad$ pa-skambin-k-it(e).

teddy-bear:voc.PL PFX-call-IMP-2PL

'Teddy-bears, please call!'

In total, 36 verbs with morphologically motivated clusters (across morpheme boundaries) were chosen for the production task. Transcription of the verbs used in the infinitive, future and imperative allowed us to compare the accuracy of production of morphonotactic, morphonotactic default and monomorphemic legal consonant clusters.

\subsection{Repetition task}

The following types of consonant clusters were included in the repetition task:

- morphonotactic default medial clusters $k s, l s, m t, \check{s} t$, $l k$ (types (b), (c) according to morphonotactic classification, see chapter 2),

- monomorphemic legal medial clusters $n k, s k, k t$, st (type (d) according to morphonotactic classification).

Clusters of both types were used within morphemes and across morpheme boundaries, as in (4)-(7).
(4) Šitas
keks-as
skanus.
this:NOM.SG
cake-NOM.SG
tasty-NOM.SG
'This cake is tasty.'
(5) Ką tu veik-s-i rytoj?
what you do-FuT-2SG tomorrow
'What are you doing tomorrow?'
(6) Nakt-i visi miega.
night-ACC.SG all sleep:PRs.3
'Everyone sleeps at night'.

\footnotetext{
7 If the child used some kind of light verb construction or pronouns instead of the expected form (i.e. 'Do you like to do it?', 'Do you like it?') we asked him 'To do what?', requiring him to use the target verb.
} 
(7) Šok-ti man patinka.

dance-INF I:DAT like:PRS.3

'I like dancing'.

In total, 36 sentences with morphonotactic default and monomorphemic legal clusters were presented to the participants during the testing. The participants were asked to repeat every sentence aloud while their reproduction was recorded. The task included warm-up sentences and fillers without any clusters. By transcribing the answers and coding the errors, we were able to analyse phonological reproduction accuracy in children of different age groups and to compare the production of clusters within morphemes and across morpheme boundaries.

\section{Results}

\subsection{Production task}

As previously mentioned, the main aim of this paper is to test the statement that morphonotactic clusters are better retained during production than phonotactic clusters as they carry significant morphological information. Figure 2 indicates the percentage of incorrect responses for different cluster types according to the morphonotactic classification (see Chapter 2).

The results regarding the types of consonant clusters were as expected. It was observed that prototypical morphonotactic clusters (monomorphemic illegal) which are exclusively due to morphological operations were produced with high accuracy by TD children in various age groups. The percentage of errors made by $3-4$ year-old children was $6 \%$. More complicated for 3-4 year-old children were monomorphemic legal and morphonotactic default clusters (14\% and $17 \%$ incorrect responses). 4-5 year-old TD children performed much better than the children of age group 3-4 in the production of all categories, especially prototypical morphonotactic clusters ( $3 \%$ incorrect responses) and monomorphemic legal clusters (3\% incorrect responses). Nevertheless, they still made a lot of errors while producing morphonotactic default clusters (12\%). Furthermore, when we compare the different TD groups, we can see that the number of errors decreases with age. At age 5-6 and 6-7, TD children are able to produce different types of consonant clusters rather well, that is, for morphonotactic clusters the percentage of incorrect responses is $3 \%$ in the $5-6$ age group and $2 \%$ in the 6-7 age group. Incorrect production of monomorphemic legal clusters comprises $0 \%$ and $2 \%$ in the 5-6 and 6-7 age groups, respectively. 5-6 and 6-7year-old participants produced morphonotactic default clusters with high accuracy; incorrect responses comprised only $1 \%$ and $0.5 \%$, respectively.

In summary, these results suggest that the high ability to produce consonant clusters develops only at age $5-6$. The prototypical morphonotactic clusters seem to be acquired earlier than the morphonotactic default and legal monomorphemic clusters. There are some errors observed in the youngest groups even in the production of morphonotactic clusters, however, 3-5 years old TD children produce them accurately in $95 \%$ of the trials.

Continuing the analysis of the results of the production task, we see that some more findings seem quite interesting. The results indicate that errors with different 
types of clusters differ considerably between the SLI and TD children. It was shown that SLI children perform worse than all the other groups of children (even than children of the 3-4 age group) in the production of morphonotactic clusters (see Figure 2).

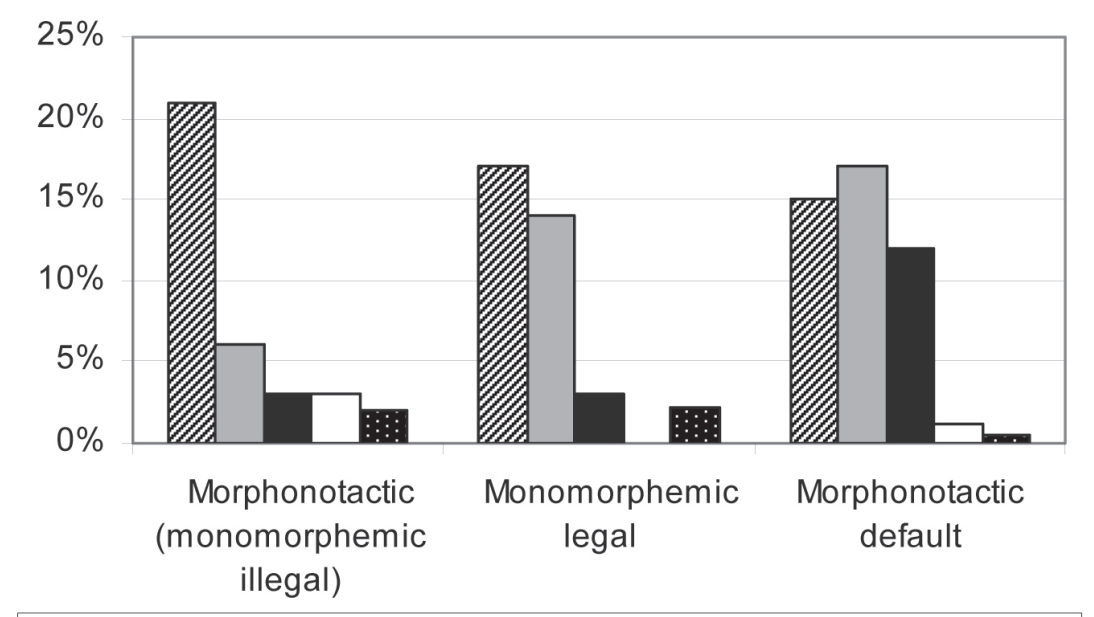

ஐ SLI $\square$ 3-4 years $\square$ 4-5 years $\square$ 5-6 years $\mathbf{0}$ 6-7 years

Figure 2. Distribution of errors in morphonotactic, morphonotactic default and monomorphemic legal clusters in the production task

The number of errors made by 6-7 year-old SLI children is $22 \%$, far greater than the $6 \%$ of errors made by $3-4$ year-old TD children. Monomorphemic legal clusters, which exist due to morphology as well as without interaction with morphology, also pose problems to SLI children. SLI children make more errors with monomorphemic legal clusters than do TD children of all age groups. For instance, the percentage of errors in the SLI group is $17 \%$, whereas in the 3-4 year-old TD group it is $14 \%$. The biggest difference is shown when we compare the results of 6-7 year-old SLI subjects (17\% errors) with the results of 6-7 year-old TD subjects ( $2 \%$ errors). The simplest category for the SLI children is morphonotactic default clusters, i.e. the number of errors is $15 \%$, similar to the results from the 3-4 year-old TD children (17\%). Despite the fact that SLI children do make many errors with morphonotactic default clusters, this category of consonant clusters does not pose as many problems for them as prototypical morphonotactic clusters do. These results run counter to the results from the TD children, who find morphonotactic default clusters the most difficult to produce (4-5 year-olds still make errors producing them $12 \%$ of the time).

These findings justify the claim that SLI children perform better on monomorphemically legal clusters than on monomorphemically illegal clusters (Marshall, van der Lely 2006). Based on this statement, it is assumed that the SLI children, contrary to the TD children, are not that sensitive to the morphological information carried by morphonotactic clusters. 


\subsection{Repetition task}

The results obtained during the repetition task reveal several main tendencies. Figure 3 indicates the percentage of incorrect responses for each of the target groups. The evidence suggests that SLI children performed worse than all the other groups of children in the repetition of both types of clusters. Reproduction errors of the 6-7 year-old SLI children are similar to those made by 3-4 year-old TDs. The most difficult category for SLI children was monomorphemic legal clusters existing both due to morphology and without interaction with morphology. As we see in Figure 3 , monomorphemic legal clusters were incorrectly produced more often than morphonotactic default clusters (where there are only few cases of phonotactic usage) not only by SLI but by TD children as well. Although the difference between the production of the two cluster types is not significant (12\% and $16 \%$ errors in the SLI group, $8 \%$ and $13 \%$ in the age 3-4 TD group, $2 \%$ and $4 \%$ in the age $4-5$ TD group, $1 \%$ and $1 \%$ in the age $5-6$ TD group, $1 \%$ and $0 \%$ in the age $6-7$ TD group), it is hypothesized that a more detailed analysis would show a bigger difference in the production of morphonotactic and monomorphemic clusters.

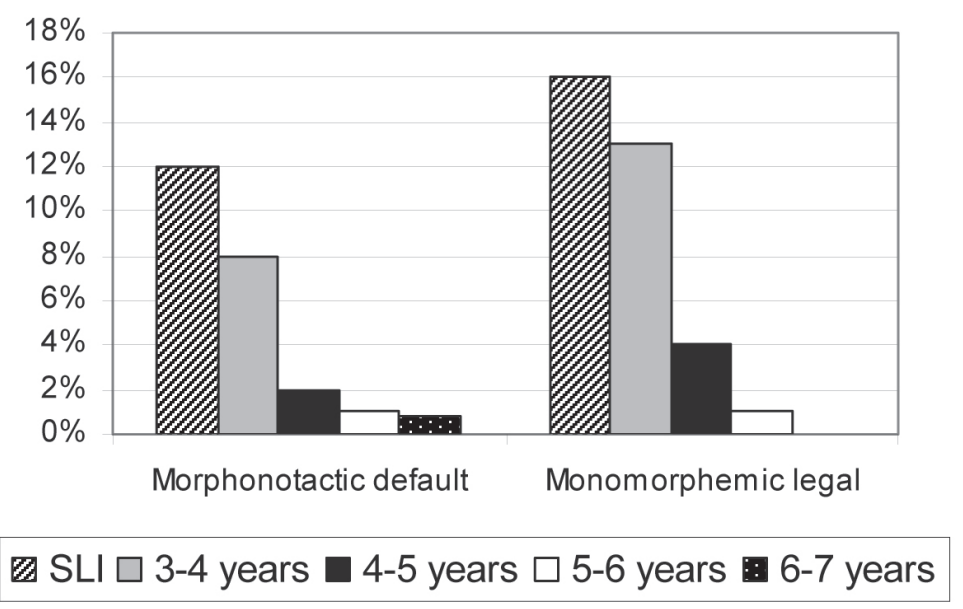

Figure 3. Distribution of errors in morphonotactic default and monomorphemic legal clusters in the repetition task

Tables 5 and 6 provide detailed comparisons of the cluster pairs that are of most interest to us, i.e. clusters within morphemes and across morpheme boundaries. Table 5 presents the morphonotactic default clusters within morphemes (phonotactic) versus across morpheme boundaries (morphonotactic), indicating the most complicated cases.

Table 5 shows the distribution of the participants' incorrect responses to the morphonotactic default clusters $k s, l s, m t, s t$, and $l k$. It can be seen that the percentage of incorrectly produced phonotactic clusters (within morphemes) is much higher in comparison with morphonotactic clusters across morphemes. For phonotactic $k s$ the percentage of incorrect responses reached about $30 \%$ and for morphonotactic $k s$ 18\%. Incorrect production of the consonant cluster ls within morphemes comprised about $15 \%$ whereas across morpheme boundaries the error rate was about $5 \%$. The participants produced the morphonotactic cluster $m t$ with maximum accuracy ( $0 \%$ errors), although the phonotactic cluster $m t$ is more 
difficult to master, as the incorrect responses comprise about 10\%. The consonant cluster $\check{s} t$ was produced accurately (100\% accuracy) when it occurred across morpheme boundaries. The phonotactic cluster št (within morphemes) was produced incorrectly in $5 \%$ of cases. For the cluster $l k$, however, the opposite tendency was observed. Incorrect responses with the phonotactic $l k$ and morphonotactic $l k$ comprised around $8 \%$ and $15 \%$ respectively. The latter item of evidence could be explained by the rare usage of the plural imperative second person in natural speech. In sum, these findings suggest that morphonotactic default clusters which occur within morphemes (phonotactic function) are more difficult to produce than morphonotactic default clusters across morphemes, except for $l k$ being used for a grammatically complex and rare imperative form. Moreover, these sets of data confirm the Strong Morphonotactic Hypothesis stating that morphonotactic clusters stand a better chance of being articulated correctly than do phonotactic clusters.

Table 5. Morphonotactic default clusters

\begin{tabular}{|c|c|c|}
\hline Cluster & Type & Error rate \\
\hline \multicolumn{3}{|c|}{ Future } \\
\hline \multirow{2}{*}{ ks } & within morpheme & $30 \%$ \\
\hline & across morphemes & $18 \%$ \\
\hline \multirow{2}{*}{ Is } & within morpheme & $15 \%$ \\
\hline & across morphemes & $5 \%$ \\
\hline \multicolumn{3}{|c|}{ Infinitive } \\
\hline \multirow{2}{*}{$m t$} & within morpheme & $10 \%$ \\
\hline & across morphemes & $0 \%$ \\
\hline \multirow{2}{*}{$s ̌ t$} & within morpheme & $5 \%$ \\
\hline & across morphemes & $0 \%$ \\
\hline \multicolumn{3}{|c|}{ Imperative } \\
\hline \multirow{2}{*}{ Ik } & within morpheme & $8 \%$ \\
\hline & across morphemes & $15 \%$ \\
\hline
\end{tabular}

Table 6 provides the percentages of incorrect usage of monomorphemic legal clusters which exist both due to morphology and without interaction with morphology.

Table 6. Monomorphemic legal clusters

\begin{tabular}{|c|c|c|}
\hline Cluster & Type & Error rate \\
\hline \multicolumn{3}{|c|}{ Imperative } \\
\hline \multirow{2}{*}{$n k$} & within morpheme & $15 \%$ \\
\hline & across morphemes & $20 \%$ \\
\hline \multirow{2}{*}{$s k$} & within morpheme & $25 \%$ \\
\hline & across morphemes & $25 \%$ \\
\hline \multicolumn{3}{|c|}{ Infinitive } \\
\hline \multirow{2}{*}{$k t$} & within morpheme & $15 \%$ \\
\hline & across morphemes & $15 \%$ \\
\hline \multirow{2}{*}{ st } & within morpheme & $5 \%$ \\
\hline & across morphemes & $5 \%$ \\
\hline
\end{tabular}


We can clearly see that the accuracy of production of clusters within morphemes and across morphemes is very similar (phonotactic $n k 15 \%$ errors, morphonotactic $n k$ 20\% errors; phonotactic sk 25\%, morphonotactic sk 25\% errors; phonotactic $k t$ 15\%, morphonotactic $k t$ 15\% errors; phonotactic st $5 \%$, morphonotactic st $5 \%$ errors). Such results are to be expected, because monomorphemic legal clusters exist both due to morphology and without interaction with morphology. This means that unlike morphonotactic default clusters, children using monomorphemic legal clusters across morphemes are not sensitive to the function fulfilled by a morpheme because the cluster occurs often in a monomorphemic context.

To summarize the results of the repetition task, children perform better at morphonotactic default clusters across morpheme boundaries than at morphonotactic default clusters within morphemes. Analysing monomorphemic legal clusters, no differences were found in children's performance at repeating clusters across morphemes and clusters within morphemes. Such results may imply that children are more sensitive to morphological information carried by clusters that appear very rarely in monomorphemic contexts.

\section{Conclusion}

The main goal of the present study was to demonstrate the interaction between morphology and phonology, as well as to explore the relationship between the acquisition of phonotactics and the acquisition of morphology. For this purpose, experimental data collected from 60 TD children of four age groups and 11 SLI children were analyzed.

Although this study was conducted on a relatively small number of subjects, it has explored the impact of morphology on the acquisition of phonotactics. A comparison of behaviour of morphonotactic (monomorphemic illegal), morphonotactic default and monomorphemic legal consonant clusters suggest that each of the categories poses different challenges to the child. It is demonstrated that TD children process morphonotactic clusters more accurately than morphonotactic default clusters and monomorphemic legal clusters because morphonotactic clusters have the function of co-signalling the existence of a morphological rule. Morphonotactic default clusters perform this function less adequately, as is shown by the results of the production task. As we have seen, morphonotactic default clusters pose more problems than morphonotactic clusters for TD children. Monomorphemic legal clusters do not co-signal the function of a morphological rule, thus the accuracy in producing these clusters within morphemes and across morphemes is very similar.

The findings that children with SLI perform worse than TD children on all categories of consonant clusters are most probably not surprising. As the results of repetition and production tasks indicate, $6-7$ year-old SLI children match TDs who are 3-4 years old. However, children with SLI behave differently while producing consonant clusters. In contrast to TD children, for SLI children prototypical morphonotactic clusters are the most difficult, as SLI children are not sensitive to morphological information carried by morphonotactic clusters. These findings supplement the statement of Marshall and van der Lely (2006) that SLI children perform better on monomorphemically legal clusters than on monomorphemically illegal clusters. 
In sum, this study strengthens and expands the Strong Morphonotactic Hypothesis, according to which speakers use morphonotactic consonant clusters as morphological boundary signals. The study supports the assumption that morphonotactic clusters are better retained in production than phonotactic clusters, as they carry significant morphological information which facilitates the processing of consonantal structures. These findings are related to the theory of coherent feature selection which claims that children, when listening to the speech of adults, first notice natural elements and those elements of the language that denote a particular function or have an exceptional feature (Dressler et al. 1995: 19, Wurzel 1984: 21).

The results also suggest directions for future research, e.g. checking whether the accuracy of production of morphologically motivated clusters holds steady when measured using bigger and more varied samples. Furthermore, some additional factors in the acquisition of consonant clusters were not explored here at all, namely the position of the cluster in the word, frequency or phonotactic markedness. Further work is planned to test these factors and to develop the test on (mor)phonotactics so that it can become a useful tool for both clinical and research purposes.

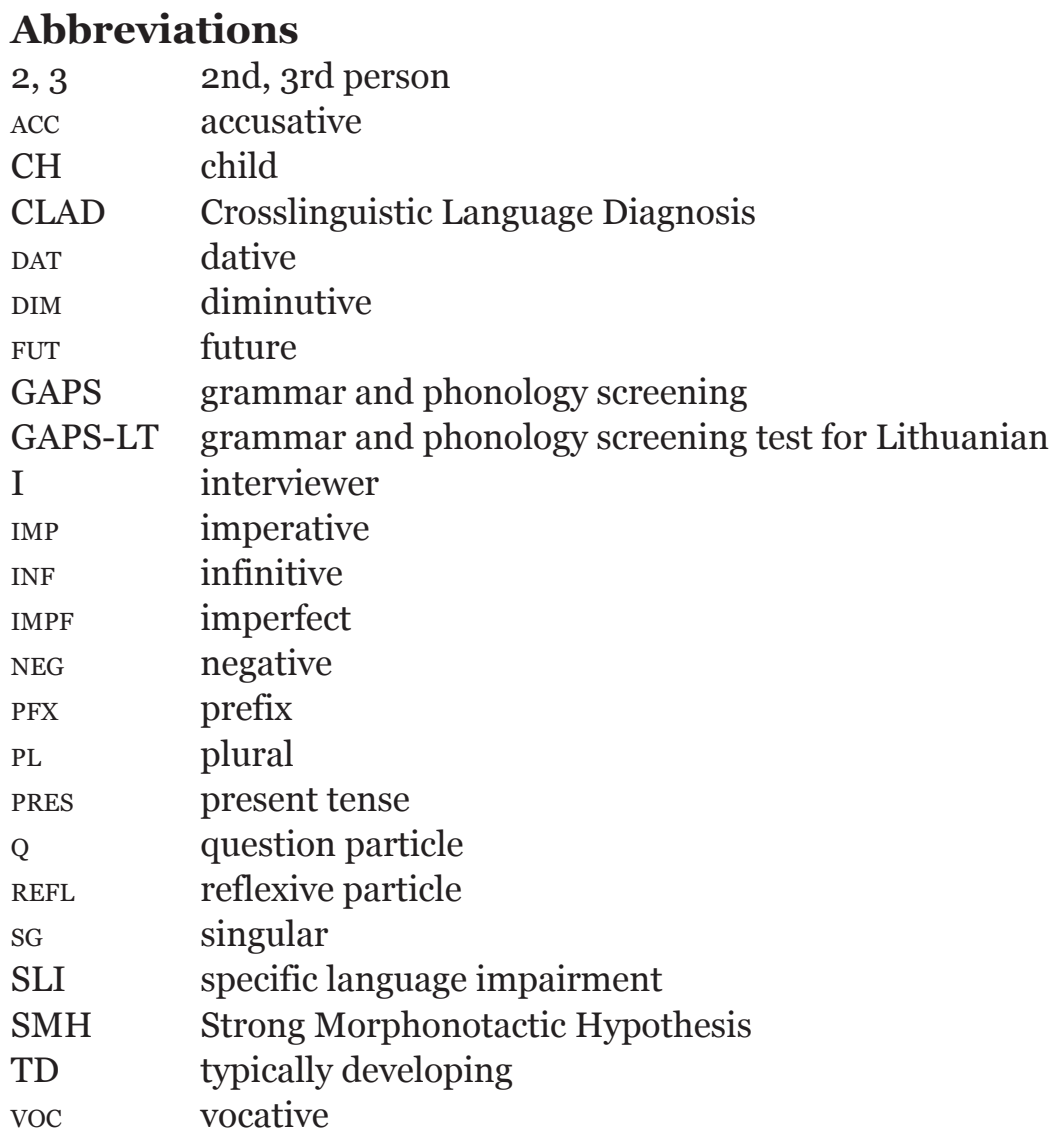

\section{References}

Calderone, Basilio; Celata, Chiara; Korecky-Kröll, Katharina; Dressler, Wolfgang U. 2014. A computational approach to morphonotactics: Evidence from German. - Language Sciences, 46 (Part A), 59-70. http://dx.doi.org/10.1016/j.langsci.2014.06.007

Dressler, Wolfgang U.; Mayerthaler, Willi; Wurzel, Wolfgang U.; Panagl, Oswald 1987. Leitmotifs in Natural Morphology. Studies in Language Companion Series 10. Amsterdam: Benjamins. $\underline{\text { http://dx.doi.org/10.1075/slcs.10 }}$ 
Dressler, Wolfgang U.; Drażyk, Roberta and Danuta; Dziubalska-Kołaczyk, Katarzyna; Jagła, Ewelina 1995. On the earliest stages of acquisition of Polish declension. - Wiener Linguistische Gazette, 53-54, 1-21.

Dressler, Wolfgang U.; Dziubalska-Kołaczyk, Katarzyna 2006a. Proposing morphonotactics. Rivista di Linguistica, 18 (2), 249-266.

Dressler, Wolfgang U.; Dziubalska-Kołaczyk, Katarzyna 2006b. Proposing morphonotactics. - Wiener Linguistische Gazette, 73, 69-87.

Dressler, Wolfgang U.; Dziubalska-Kołaczyk, Katarzyna; Pestal, Lina 2010. Change and variation in morphonotactics. - Folia Linguistica, 31, 51-67.

Freiberger, Eva Maria 2007. Morphonotaktik im Erstspracherwerb des Deutschen. - Wiener Linguistische Gazette, 74, 1-23.

Gaulienė, Veronika; Giedrienė, Regina; Grikainienė, Loreta 2000. Kalbos tyrimas. [Language screening.] Vilnius.

Hurch, Bernhard; Rhodes, Richard (Eds.) 1996. Natural Phonology: The State of the Art. Berlin: Mouton de Gruyter. http://dx.doi.org/10.1515/9783110908992

Kamandulytè, Laura 2006a. Morfonotaktikos įsisavinimas. [The acquisition of Morphonotactics.] - Žmogus ir žodis, 8 (1), 84-88.

Kamandulyte, Laura 2006b. The acquisition of morphonotactics in Lithuanian. - Wiener Linguistische Gazette, 73, 88-96.

Korecky-Kröll, Katharina; Dressler, Wolfgang U.; Freiberger, Eva Maria; Reinisch, Eva; Mörth, Karlheinz; Libben, Gary 2014. Morphonotactic and phonotactic processing in German-speaking adults. - Language Sciences, 46 (Part A), 48-58. http://dx.doi. org/10.1016/j.langsci.2014.06.006

Lely, Heather K. J. van der; Gardner, Hilary; Froud, Karen; McClelland, Alastair G. R. 2007. The grammar and phonology screening (GAPS) test. London: www.DLDCN.com.

Leonard, Laurence B. 1998. Children with Specific Language Impairment. Cambridge, Mass: The MIT Press.

Marshall, Chloe R.; Lely, Heather K. J. van der 2006. A challenge to current models of past tense inflection: The impact of phonotactics. - Cognition, 100 (2), 302-320. http:// dx.doi.org/10.1016/j.cognition.2005.06.001

Ruzaitè, Jūratė; Dabašinskienè, Ineta 2010. Specific language impairment: Adaptation of a screening test for Lithuanian. - Darbai ir dienos, 54, 277-300.

Zydorowicz, Paulina 2007. Polish morphonotactics in first language acquisition. - Wiener Linguistische Gazette, 74, 24-44.

Zydorowicz, Paulina 2010. Consonant clusters across morpheme boundaries: Polish morphonotactic inventory and its acquisition. - Poznań Studies in Contemporary Linguistics, 46 (4), 565-588. http://dx.doi.org/10.2478/v10010-010-0028-0

Wurzel, Wolfgang U. 1984. Flexionsmorphologie und Natürlichkeit. Berlin: Akademie-Verlag.

\section{Web references}

CLAD = Crosslinguistic Language Diagnosis. European project on the study of Specific Language Impairment and Dyslexia. http://www.cladproject.eu/ (24.2.2015).

Corpus of Spoken Lithuanian. http://donelaitis.vdu.lt/sakytines-kalbos-tekstynas/ (24.2.2015).

Laura Kamandulytè-Merfeldienè (Vytautas Magnus University). Her research interests include corpus linguistics, psycholinguistics, first and second language acquisition, and specific language impairments.

K. Donelaičio 58, 44248 Kaunas, Lithuania

I.kamandulyte-merfeldiene@hmf.vdu.lt 


\section{MORFONOTAKTIKA LEEDU KEELE OMANDAMISEL ESIMESE KEELENA: TÜÜPILISE ARENGUGA VS. SPETSIIFILISE KÕNEARENGUPUUDEGA LAPSED}

\section{Laura Kamandulytè-Merfeldienè}

Vytautas Magnuse Ülikool

Artikkel käsitleb fonotaktiliste ja morfonotaktiliste konsonantühendite omandamist leedu keeles. Eesmärgiks on kontrollida tugevat morfonotaktilist hüpoteesi, mille järgi keelekõnelejad kasutavad morfonotaktilisi konsonantühendeid morfoloogiliste piiride signaalidena (Korecky-Kröll jt 2014, Calderone jt 2014: 59). On oletatud, et morfonotaktilised konsonantühendid on morfeemide funktsionaalsuse tõttu keelekasutuses püsivamad kui puhtfonotaktilised ühendid.

Rikka tuletus- ja muutemorfoloogiaga fusiivse keelena pakub leedu keel erilist huvi morfonotaktika omandamise uurimisele. Varasem, ühe leedu lapse keeleomandamise pikiuuring kinnitas hüpoteesi, et morfonotaktilised konsonantühendid omandatakse varem ja kergemini kui puhtfonotaktilised. Siinne uuring põhineb katseandmetel 60 eakohase arenguga ja 11 spetsiifilise kõnearengupuudega (SKAP) lapselt. Ülesandeks on uurida morfoloogia mõju fonotaktika omandamisele ja kontrollida seisukohta, et SKAP-lapsed tulevad monomorfeemsete legaalsete konsonantühenditega paremini toime kui monomorfeemsete illegaalsete ühenditega (Marshall, van der Lely 2006).

Uurimistulemused näitavad, et eakohase arenguga lapsed töötlevad morfonotaktilisi konsonantühendeid täpsemalt kui fonotaktilisi, sest morfonotaktilised ühendid annavad märku morfoloogiareeglist. Seevastu SKAP-lastele on morfonotaktilised ühendid kõige raskemad; põhjuseks võib pidada seda, et SKAP-lapsed ei tunne ära nende ühenditega kaasnevat morfoloogilist informatsiooni.

Võtmesõnad: morfonoloogia, konsonantühend, fonotaktika, morfeem, morfeemipiir, leedu keel 